\title{
Research on the application of Lean production mode in enterprises Take Desi fogg company for example
}

\author{
Xiaoli JI \\ ${ }^{1}$ Dalian University of Science and Technology School of Economics and Management, Dalian, China.
}

\begin{abstract}
Lean production is the third milestone of industrialization in human history. This is a revolutionary production and operation practice. Its core idea is to reduce waste, establish an efficient production system, improve corporate profits. It represents the direction in which manufacturing, or manufacturing standards, are moving today. With the continuous advancement of the information revolution, manufacturing enterprises must re-integrate external environmental information, transform their ideas and methods, and at the same time use big data and artificial intelligence to strengthen the manufacturing industry and form a new production mode.

This article expounds the theory of lean production and basic methods from the perspective of big data and artificial intelligence. It combined with desi fogg existing organizational structure, site management, quality management, product development, production organization, problems existed in the aspects of applied research in the core of lean production ideas and principles, proposed the desi fogg lean production plan, and solve the management problems of the production process and waste of resources, establish the enterprise system of lean production system, and improve the level of the site management v production quality and enterprise competitiveness.
\end{abstract}

\section{Background and significance of lean production implementation in automobile manufacturing enterprises}

Lean production, a form of production management from Toyota motor Corp., aims to minimize "extravagance" in everything, including inventory. Centering on this goal, Toyota Motor Corporation has been exploring methods and measures while developing itself, and has gradually formed a set of unique production, operation and management mode. At that time, many production methods represented advanced management ideas and methods. Using a large number of specialized equipment and adopting a large number of specialized production mode is the main way to reduce costs and enhance competitiveness. The main goal of lean production is to achieve zero inventory, the key goal is to eliminate waste, the long-term goal is to keep the system agile and flexible, and the ultimate goal is to achieve zero defects.

Most of the big carmakers are adopting lean production, adopting "just-in-time" (JIT) practices and strengthening collaboration. In particular, some enterprises even surpass Japanese enterprises in the improvement of some production methods. In addition to the automobile industry in other industries, more and more enterprises also widely absorb and promote the fine methods of organization, personnel management and joint venture methods. With the constant change of people's demands, personalized order production makes lean production must combine big data analysis and artificial intelligence to realize a new production mode that is accurate, efficient and economical.

In recent years, we can see the great influence of lean production thought from the personnel management reform and enterprise reengineering activities in many enterprises around the world.

\section{Big data + artificial intelligence + Lean production}

There is no doubt that advanced manufacturing methods and management methods can improve production efficiency. In order to seek efficient production mode, we need to use big data and artificial intelligence to achieve the goal of lean production. Optimize the production chain by simplifying, merging, combining, replacing and changing the linkage between business processes. By changing man-machine combination mode, intelligent equipment can replace manual operation and optimize process to realize process simplification, so as to improve production integration efficiency. Through big data analysis and feedback mechanism, management closed loop is formed to achieve accurate and efficient production. The application of feedback data control technology, the establishment of process feedback data control system, so 
that each process operation in a controllable state, by changing the input factors and control variables, the operation of each process real-time control, timely solve the problems in the process operation, the overall coordination of the operation of each process. When the running state of the process deviates from the control target, it should be adjusted timely.

Modern manufacturing enterprises should not be limited to the improvement of management level to achieve lean production, but should use high-tech and scientific analysis methods, and use the combination of big data and artificial intelligence to achieve the current lean production mode. For different industries, different manufacturing enterprises, different market customer models, different product processes, and different manufacturing management basis, the emphasis of manufacturing mode is also different. Manufacturing enterprises should gradually change the manufacturing mode according to the actual situation.

\section{Production and operation status of Desivogel}

Founded in 1938, Desivogel Auto parts manufacturing Group is an international German company headquartered in Danklingen, Near Munich, Germany. It is one of the global auto parts suppliers in the field of steel and aluminum forging and finishing.

\subsection{Organizational structure and production process}

In terms of administrative positions, the general manager is under the management of the chairman; sales, production, technology, finance and administrative departments are under the direct management of the general manager, and the five department managers manage 2-3 positions each. In the event of production problems, the sales, production, technical, financial and administrative departments shall directly refer to the general manager for approval before handling them. But in the workshop management, the workshop director can directly manage each shift each working procedure, can directly manage to the workshop staff, do not need to ask the general manager.

In the production process, each functional department plays its role. But there are some differences because the technical department is subordinate to the supervisor who is directly managed by other departments. In each process of the manufacturing workshop, the quality control process is assigned to the production department, which connects the communication between the workshop and the technical department. Once problems are encountered, the joint communication between the three parties turns into unilateral communication between the production department, the workshop and the technical department. The conclusion takes too long, which leads to a waste of time and an increase in cost. The same is true for equipment repairs, which take a long time and require waiting for final repairs.

The production process of Desivogel auto parts adopts flow operation, the specific process is shown in the figure:

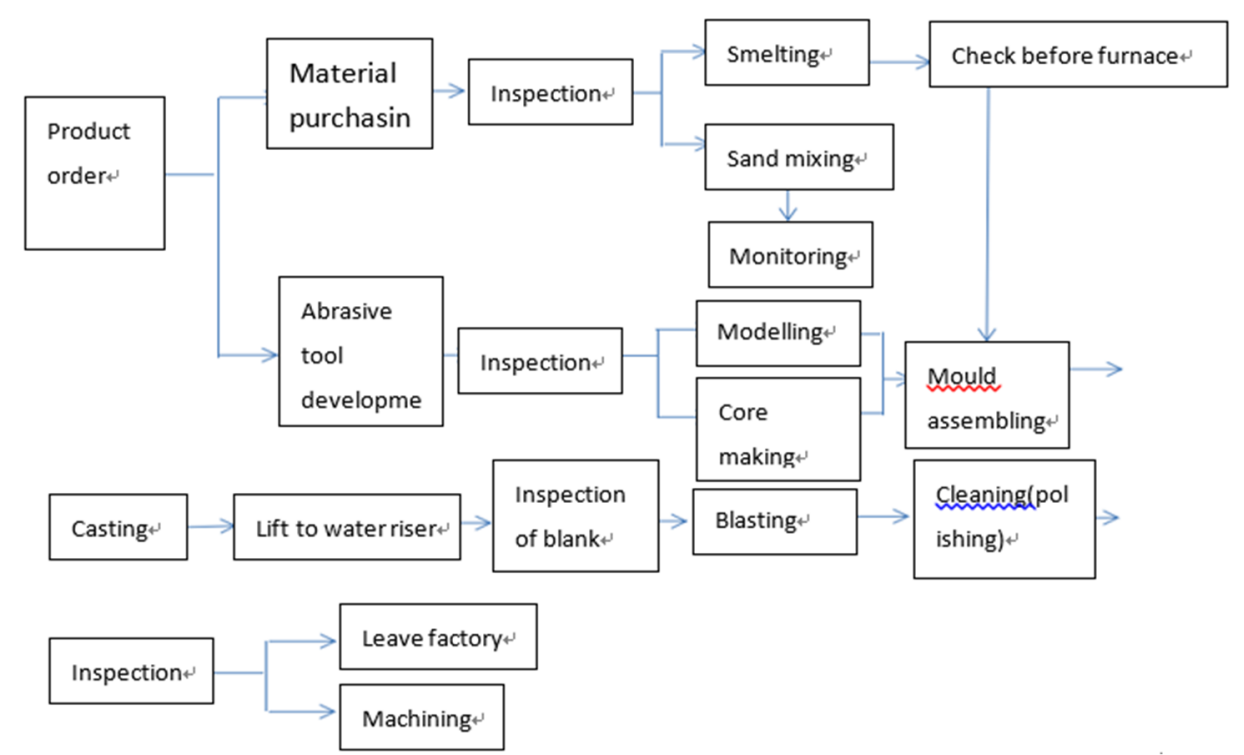

Fig 1. Production flow chart

\subsection{Product quality control}

Raw material prices continue to rise. Due to the high labor costs in the traditional production bases of Western Europe, Central and Eastern Europe and China have become the main areas for German automobile industry to move abroad. The quality process of Desivogel parts production is reflected in quality. Desivogel's product quality improvement staff is dedicated to helping product performance, while quality engineers provide technical assistance to the production process. In other words, it is used for cold forging, warm forging, hot forging, precision aluminum alloy casting and precision machining of steel automobile parts, providing customers with a series of key automobile parts from precision forging to precision forming. Processing and installation, batch inspection and 
control; The quality inspection of the production process in the production line will be carried out at a later stage.

\subsection{Product development and management}

With the globalization of the world, the market demand for new products is increasing, so the market needs to develop new products. The technical r\&d department and engineers of Desivogel are responsible for new product development and innovative product development using materials manufacturing technology. The average product development cycle of Desivogel is 1-3 years. Desivogel USES a variety of production methods to develop each component and scale production types; The development of each special product of Desivogel is generally decided and voted by the company's senior management through the meeting, adopting the principle of minority subject to the majority, and the chairman can vote with one vote; The draft was approved by the vote and sent to the general manager's office. The general manager distributed it to the five department managers' offices. Finally, the technical department distributed it to the R\&D department and the engineers for development.

\subsection{Product site management}

From the point of production site, desi fogg mode of production mode to mass production, it belongs to the typical push type mode of production, the work time control at 9 o 'clock in the morning - 18 PM period, each workshop has more than one workshop director and group leader production on-site monitoring process, sometimes often to move in the parts in the workshop, site managers daily work tasks according to the company the production field management measures of site supervision and management rules and regulations; Management personnel for the unqualified products and defective products are unified to draw out into the category of products not allowed to leave the factory.

\subsection{Inventory management}

After the company receives the order, relevant personnel will purchase raw materials according to the company's production needs and organize production. But this still does not get rid of the "push production" mode of production organization, because production is driven by demand, the production line is completely determined by demand. When the raw materials needed for production arrive, the production planner will assign the first step and the production will start from the first step. Auto parts production process is complex, from the product forming to the final sand cleaning (grinding) product inspection factory is the assembly line. The advantage of this method of production is that the workers in each process perform their respective duties, which improves the production efficiency. However, the disadvantage is that when problems occur in the current process and the production cannot continue, the information cannot be timely transmitted to the previous process and the production will not stop, which may easily lead to overstock of products.

\subsection{Current situation of production and manufacturing system}

Dzivog, an auto-parts supplier based in Dunklingen, Bavaria, has seen annual sales growth of about $16 \%$ a year for a decade. It is the leader in the world's fastest-growing SMB market. Growing demand is always accompanied by a new set of challenges. Their vision is to improve on these new challenges and provide sensible solutions. Desivogel is another traditional industrial parts manufacturer that has established a feeding manufacturing business.

It has two production systems and established a 3D printing service based on market research. IGUS is involved in two parts of additive manufacturing business, including wire production engineering $3 \mathrm{D}$ printing and assembly system, providing customized 3D manufacturing and printing service system for bearing, drive nut and other industrial parts to produce unique parts or small series of parts for users.

\section{Desivogel's necessity to implement lean production}

\subsection{Make full use of desivogel's excellent human resources}

By pulling in effective users, the queue will usually be mass-produced into a continuous process, greatly increasing the labor productivity of the system and greatly reducing the production time of the whole system.

\subsection{Can solve the quality problem of Desivogel products}

The product quality will be more in line with the market demand, at the same time reduce the production process waste, reduce the occurrence of accidents. According to the data, under the lean economic model, product quality can be improved by three times, and waste products and industrial accidents can be reduced by more than $45 \%$.

\subsection{It can shorten the product development cycle of Desivogel}

Due to the production design and development of parallel works, according to statistics: can shrink the development cycle $50 \%$ to $70 \%$, save research and development funds $30 \%$ to $40 \%$, reduce the disposal and repair more than $50 \%$, the number of design changes to reduce more than $50 \%$ and make the product with outstanding technology and standardization degree.

\subsection{Can solve the problem of Desivogel inventory management}

Lean production pursues zero inventory production, so the capital occupation is greatly reduced, and the production cycle shrinks. And finished goods inventory and production costs are very low. Because it is only a time of strict production and demand, inventory reflects a 
quarterly level of production. With zero inventory as the goal, the manufacturing cost of the product can be effectively reduced according to the requirement of zero defect.

\section{Desivogel's strategy and Suggestions for implementing lean production}

\subsection{The production process takes advantage of cloud computing and big data to solve production problems}

Desi fogg should take advantage of cloud computing, big data of has happened, is happening, impending demand analysis, make production plan and forecast, orders for the production of this kind of mode of production namely business is began, after to receive customers' orders and procurement, through manufacturing and distribution to promote the production of the enterprise, in other words, production and sales are synchronous, and even the prophet, production speed changes to data analysis after may demand as the foundation, so you can keep the balance of the logistics. Material flow according to order, high logistics efficiency can effectively eliminate inventory waste.

\subsection{Improve product qualification inspection standards, rational use of artificial intelligence, to ensure product quality}

Throughout the production process, each task emphasizes quality, which is the key to a lean production system. Lean production method is introduced into the enterprise, and relevant personnel apply its management ideas to the whole process of production, so as to further improve the production process and improve the production quality of products. And conduct quality control in each production link, emphasizing process, not just inspection. Fully implement the use of management tools, optimize the existing process, refine quality control points, control and improve the quality of each link, to ensure and improve product quality. Carry out lean production team activities in depth and continuously, organize all members to participate, focus on the company's policy objectives and on-site problems, so as to improve quality and reduce consumption.

At the same time, rational use of artificial intelligence, intelligent equipment or robots to replace regular, repetitive operations, so that not only improve production efficiency, but also improve the precision of production, to ensure the quality of products play an important role.

\subsection{Optimize the mix of new and old products and intensify the development of new products}

According to the idea of concurrent engineering, the new product development team and technology center are set up to establish the new product development system. Design, manufacturing, management and other processes integrate them into an overall system for consideration. Design processes include not only design and process components, but also quality control, cost accounting, market research, and schedule generation. Incorporate all aspects of new product related processes into the new product development team and create a new product development system that involves all parties.

Develop new product development process. The development process must realize the integration and sharing of information, so the integration and sharing of information between application systems must be realized, and the information transmission, communication and coordination of various professionals must be strengthened in product development. And use product management data system to assist parallel design.

\subsection{Optimize production management structure and improve production management efficiency}

General manager, deputy general manager, corporate management, headquarters, finance, production, mechanical design, electronic design, mold design subordinate deputy general manager. From the process design to the production, the deputy general manager coordinates, so that the communication between departments can be more smooth, and problems in the production process can be solved in a timely manner. Reduce preparation time for production. It is common practice to reduce the production lead time by carefully examining all preparatory activities before the production process begins to eliminate all possible risks. List each element or step of the production preparation process and determine which are internal factors (downtime is required); Adopt industrial engineering method to improve process, reduce all internal and external factors that affect production preparation, and improve efficiency value. With this production process can be optimized, the production structure is further improved. 


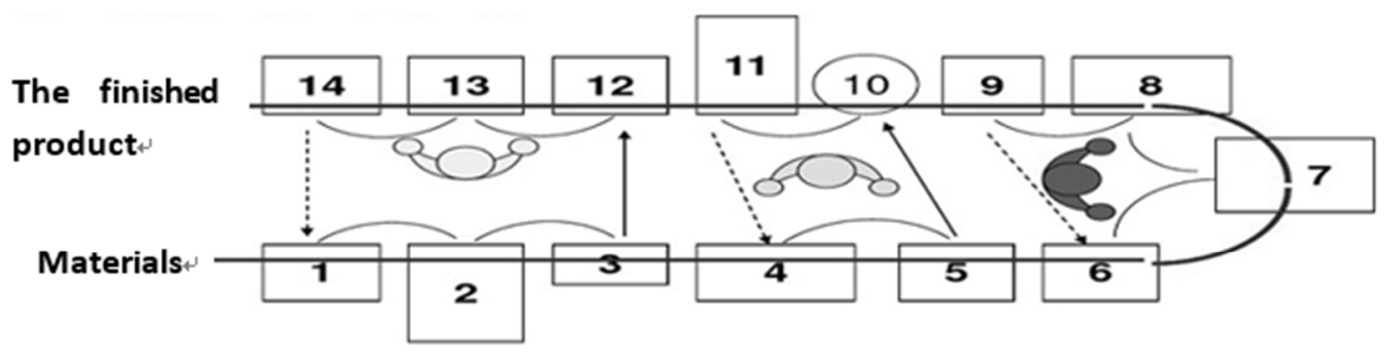

Fig.2 Optimize production line

\subsection{Improve the site management system}

\subsubsection{Improve the quality of lean production}

The first step in the successful implementation of Lean production management is to make the majority of employees understand and accept the content of lean production, characteristics, suitability and applications. Training is an effective way to achieve this goal. Accepting new management ideas is a process. Therefore, repeated, multi-level cross-training is very necessary. Another form of training is extensive and in-depth explanation and advocacy. By improving the team spirit, the enterprise can quickly transition to lean enterprise, so as to achieve the desired training effect.

\subsubsection{Maintain mechanical equipment and improve the equipment guarantee system}

Complete production and maintenance is the most solid measure to eliminate downtime, including daily maintenance, preview personality maintenance, preventive maintenance and immediate repair four basic means of maintenance. Routine maintenance - The operator and maintenance personnel of routine maintenance activities need to maintain the motor regularly. Preventive maintenance - Four analytical techniques measured with one hand are used to predict potential failures to ensure that production equipment does not lose time due to mechanical failure. The point is to prevent beforehand. Preventive maintenance preparation documentation for each machine records all maintenance records and maintenance plans. The maintenance of every part of the machine will be comprehensive, strict maintenance, timely replacement of parts, so as to ensure that there is no accident.

At present, lean production has been applied in many fields. Lean production, lean management and Lean thinking are inseparable. Lean spirit provides a spiritual pillar for lean production and lean management, and lean management provides a good guarantee for lean production, promoting each other.

Effective lean production can help enterprises improve. As long as an enterprise can keep pace with The Times, use advanced methods and tools, such as big data technology and intelligent technology, and constantly create more targeted new manufacturing mode, it will certainly help the enterprise to form the core competitiveness and achieve excellence.

\section{References:}

1. He Xin. Research on the Application of Lean Production in automobile Manufacturing Enterprises [J], Automotive Practical Technology, 2016,19,216217.

2. Guo Wenyue. Study on the Application of Lean Production Management Model in enterprises [J], Management Observation, 19,3,44-45.

3. Liu Meilian. On the Application of Lean Production in manufacturing industry [J], Research on Science and Technology Innovation and Applied Management,2016,22,158-159..

4. Shi Jingrui. Application of Lean Production Technology in automobile manufacturing industry $[\mathrm{J}]$, Times Automobile,2019,4,56-57.

5. Zhu Jianyang, Wang Sheng, Zhang Ping. Research on the Reform Strategy of large state-owned manufacturing Enterprises in the Context of Lean Production -- A Case study of Shenyang M Company [J], Internal Combustion Engine and Accessories,2019,22,142-143.

6. Wang Xi. Integration of Lean Production and Quality System [J], Standardization and Quality of Machinery Industry, 209,9,52-56. [10] Chase, Aquilano,Jacob Booth.operationsmanagement[M],Beijing:Beijing mechanical industry publishing Club,2019.

7. Markup C S. Panneerselvam R. Literature review of JIT-KANBAN system[J]. Intermational Journal of Advanced Manutacturing Technology, 2017, 32, 393408.

8. Roy Curran. Lean manufacture way synopsis[J], Bibliographief, 2015, 3, 551-571 